\title{
Shrimp Drying Characterizes Undergoing Microwave Treatment
}

\author{
Asie Farhang \\ Department of Veterinary Medicine, Tehran University, Tehran, Iran \\ E-mail: Asiyehfarhang@yahoo.com
}

Adel Hosainpour

Department of Farm Machinery Mechanical Engineering, Ilam University, Ilam, Iran

E-mail: A.Hosainpour@yahoo.com

Hosain Darvishi (Corresponding author)

Department of Mechanical Engineering, Islamic Azad University, Shahr-e- Rey Branch, Shahre Rey, Iran

Tel: 98-21-441-949-114Ｅ-mail: Hosaindarvishi@ yahoo.com

Farzad Nargesi

Department of Farm Machinery Mechanical Engineering, Ilam University, Ilam, Iran

E-mail: Farzad_nargesi61@yahoo.com

Received: October 26, 2010 Accepted: November 9, 2010 doi:10.5539/jas.v3n2p157

\begin{abstract}
In this paper, a laboratory microwave oven was used to dry the shrimp, applying microwave power in the four levels of 200, 300, 400 and 500W. Results indicated that drying took place in the falling rate period. The drying rate increased with drying microwave power, but decreased with moisture content. The effective diffusivity varied from $1.54 \times 10^{-10}$ to $1.43 \times 10^{-9} \mathrm{~m}^{2} / \mathrm{s}$. About $22.54 \%$ increase in drying efficiency and about $28.94 \%$ $\left(0.937 \mathrm{MJ} / \mathrm{kg}\left[\mathrm{H}_{2} \mathrm{O}\right]\right)$ decrease in specific energy consumption could be obtainable by increasing the microwave power from 200 to $500 \mathrm{~W}$.
\end{abstract}

Keywords: Microwave drying, Shrimp, Specific energy consumption, Effective diffusivity

\section{Introduction}

Drying is one of the oldest methods of food preservation and it is a complex process and involves simultaneous mass and heat transfer. The temperature, drying time, moisture diffusivity and drying rate are vital parameters in the design of process like for instance drying, storage, aeration and ventilation, etc.

Different conventional thermal treatments are used in the drying of biologic product such as, hot-air drying, vacuum drying, sun-drying and freeze drying result in low drying rates in the falling rate period which leads to undesirable thermal degradation of the finished products (Mousa and Farid, 2002; Vadivambal and Jayas, 2007; Ozbek and Dadali, 2007).

So that compared with these drying techniques; microwave drying offers opportunities as rapid and relatively uniform heating achieved, shorter operating time, high thermal efficiency, space utilization, sanitation, energy saving, precise process control, fast start-up, shut-down conditions and high quality of the finish product (Khraisheh et al., 2004; Sharma and Prasad, 2004; Ozkan et al., 2007; Reyes et al., 2007; Varith et al., 2007).

Dried shrimp is one of the most important exported marine products in many countries such as Thailand, China, Malaysia and United States. Lin et al (1999) have compared microwave vacuum and air and freeze drying on product quality for drying of shrimp. Prachayawarakorn et al (2002) studied the drying characteristics of shrimp in drying media at the temperature range of $120-180^{\circ} \mathrm{C}$ for superheated steam and of $70-140^{\circ} \mathrm{C}$ for hot air. They reported that the shrimp dried by the superheated steam shows a higher degree of shrimp quality. 
Namsanguan et al (2005) performed the simulation of the drying process of shrimp using a superheated steam drying cabinet within the temperature range of $140-160^{\circ} \mathrm{C}$. Jayasinghe et al (2006) studied the influence of temperature range of $50-90^{\circ} \mathrm{C}$ at 1,2 and $3 \mathrm{~h}$ drying time on convective drying kinetics of cooked shrimp. They found to be preferred method of processing that salting at $5 \%$ level followed by cooking for $20 \mathrm{~min}$ and drying for $2 \mathrm{~h}$ at $70^{\circ} \mathrm{C}$. Niamnuy et al $(2008 \mathrm{a}, \mathrm{b})$ studied thin-layer drying of shrimp in a jet spouted bed dryer and found that it is affected by drying air temperatures and air flow rate. They reported that drying shrimp at higher temperature led to lower astaxanthin degradation during storage than drying at lower temperatures. Visetsuntorn and Banjong (2010) studied the drying characteristics of shrimp in a batch convective dryer at $40-70^{\circ} \mathrm{C}$ air temperatures.

Namsanguan et al (2004) and Namsanguan (2007) studied drying of shrimp at hybrid superheated steam and heat pump dryers and reported the same phenomenon in shrimp drying. Guochen et al (2009) have investigated dehydration property of shrimp undergoing heat-pump drying process. Tichangtong (2001) have studied effects of some operating parameters such as temperature, drying rates, specific energy consumption and drying efficiency on the viability of shrimp.

The influence of drying conditions upon the quality of shrimp has been investigated by Devahastin et al (2006) and Tapaneyasin et al (2005) in a jet-spouted bed dryer. In earlier work, Thanin and Salakphet (1998) performed batch drying experiments in spouted bed dryer and a combined microwave/spouted bed dryer of shrimp.

Most of the above studies examined on convective, superheated steam and heat-pump drying kinetics of shrimp. But, limited study concerning microwave drying kinetics of shrimp has been performed up to now.

Therefore, the aim of this study was to study the effects of microwave power on drying rate, specific energy consumption and drying efficiency of shrimp.

\section{Materials and methods}

\subsection{Materials}

Fresh shrimp used in this study were purchased from in Fish Bazar, Tehran, Iran and stored at refrigeration conditions $\left(-2^{\circ} \mathrm{C}\right)$ prior to experiments. shrimp had an initial moisture content of $3.103 \mathrm{~kg}\left[\mathrm{H}_{2} \mathrm{O}\right] / \mathrm{kg}[\mathrm{DM}]$, which was determined by drying in a convective oven (Memmert, DO6836, Germany) at $103 \pm 1^{\circ} \mathrm{C}$ for $4 \mathrm{~h}$ (Guochen et al., 2009).

\subsection{Experimental set-up}

Fig.1 shows the microwave drying system. The drying apparatus used consisted of a laboratory microwave oven (M945, Samsung Electronics Ins) with features of $230 \mathrm{~V}, 50 \mathrm{~Hz}$ with a frequency of $2450 \mathrm{MHz}$. Drying trial was carried out at four different microwave generation power being 200,300, 400 and $500 \mathrm{~W}$. In the measurement of temperature, K type technical iron-constant thermocouple was used with multi-meter (ET-2230/2231, Minipa, China). About $45.95 \mathrm{~g}$ of shrimp was suspended beneath a digital balance (GF-600, A \& D, JAPAN) into the microwave oven by using a mesh basket. The digital balance and was interfaced to a computer by a RS-232 cable, and the weight loss of the layer shrimp was recorded on-line every $15 \mathrm{~s}$ throughout drying using software for the balance. Three replications of each experiment were performed according to a preset microwave output power and time schedule, and the data given are an average of these results.

\subsection{Mathematical modeling}

The moisture ratio (MR) was calculated using the following equation:

$$
M R=\frac{M_{t}-M_{e}}{M_{0}-M_{e}}
$$

where MR is moisture ratio (dimensionless); $\mathrm{M}_{\mathrm{t}}$ is moisture content at $\mathrm{t}\left(\mathrm{kg}\left[\mathrm{H}_{2} \mathrm{O}\right] / \mathrm{kg}[\mathrm{DM}]\right) ; \mathrm{M}_{\mathrm{e}}$ is equilibrium moisture content $\left(\mathrm{kg}\left[\mathrm{H}_{2} \mathrm{O}\right] / \mathrm{kg}[\mathrm{DM}]\right)$; and $\mathrm{M}_{0}$ is initial moisture content $\left(\mathrm{kg}\left[\mathrm{H}_{2} \mathrm{O}\right] / \mathrm{kg}[\mathrm{DM}]\right)$.

\subsection{Effective moisture diffusivity}

Fick's second law of the unsteady-state diffusion as in equation:

$$
\frac{\partial M}{\partial t}=D_{e f f} \nabla^{2} M
$$

The solution of Fick's second law in thin layer, with the assumptions of mass transfer being by diffusion and constant diffusion coefficient were as follows: 


$$
M R=\frac{8}{\pi^{2}} \sum_{n=1}^{\infty} \frac{1}{(2 n+1)^{2}} \exp \left(-(2 n+1)^{2} \pi^{2} \frac{D_{e f f} t}{H^{2}}\right)
$$

where $D_{\text {eff }}$ is effective diffusivity $\left(\mathrm{m}^{2} / \mathrm{s}\right)$; $t$ is drying time (s); and $\mathrm{H}$ is thickness of layer (m).

When the mass transfer Fourier number is greater than 0.2, equation (3) can be simplified to equation in the form:

$$
t=\left(\frac{H^{2}}{\pi^{2} D_{\text {eff }}}\right) \ln \left(\frac{8}{\pi^{2}} \frac{M_{t}}{M_{0}}\right)
$$

The effective moisture diffusivity can be determined from the slope of the normalized plot of $\ln (\mathrm{MR})$ versus drying time.

\subsection{Drying rate}

The drying rate of the sample during drying process can be determined using the following equation:

$$
D R=\frac{M_{t}-M_{t+\Delta t}}{\Delta t}
$$

where $\mathrm{DR}$ is drying rate $\left(\mathrm{kg}\left[\mathrm{H}_{2} \mathrm{O}\right] / \mathrm{kg}[\mathrm{DM}] \mathrm{min}\right)$.

\subsection{Energy efficiency of microwave drying}

The microwave drying efficiency was calculated as the ratio of heat energy utilised for evaporating water from the sample to the heat supplied by the microwave oven (Soysal, 2004; Yongsawatdigul and Gunasekaran, 1996).

$$
\eta=\frac{m_{w} \lambda_{w}}{P t}
$$

where $\eta$ is the microwave drying efficiency (\%); $\mathrm{m}_{\mathrm{w}}$ is the mass of evaporated water $(\mathrm{kg}) ; \lambda_{\mathrm{w}}$ is the latent heat of vaporisation of water $(\mathrm{J} / \mathrm{kg})$ and $\mathrm{P}$ is the microwave power $(\mathrm{W})$. The latent heat of vaporisation of water at the evaporating temperature $\left(100^{\circ} \mathrm{C}\right)$ was taken as $2257(\mathrm{~kJ} / \mathrm{kg})$ (Hayes, 1987).

The specific energy consumption was calculated as the energy needed to evaporate a unit mass of water (Mousa and Farid, 2002; Soysal et al., 2006).

$$
Q=\frac{P t}{m_{w}}
$$

where $Q$ is the specific energy consumption $\left(\mathrm{J} / \mathrm{kg}\left[\mathrm{H}_{2} \mathrm{O}\right]\right)$.

\section{Results and discussion}

\subsection{Microwave drying kinetics}

Drying of the shrimp started with an initial moisture content round $3.103\left(\mathrm{~kg}_{\mathrm{H}}\left[\mathrm{H}_{2} \mathrm{O}\right] / \mathrm{kg}[\mathrm{DM}]\right)$ to the final moisture content of around $0.01\left(\mathrm{~kg}\left[\mathrm{H}_{2} \mathrm{O}\right] / \mathrm{kg}[\mathrm{DM}]\right)$. The variations of moisture content with drying time at different microwave powers are given in Fig. 2. As seen in Fig. 2, a reduction in drying time occurred with the increasing microwave power level. The drying time reduced by $2.94,2.04$ and 1.62 times in the drying treatment realized at 500,400 and $300 \mathrm{~W}$ microwave powers compared with the drying treatment realized at $200 \mathrm{~W}$ microwave powers.

Fig. 3 shows the effect of microwave power on moisture ratio of shrimp. The increase in the microwave power decreased moisture ratio rapidly and decreased drying time. Microwave drying at 200, 300, 400 and 500W required $5.38,3.25,2.58$ and $1.78 \mathrm{~min}$, respectively for reducing the moisture ratio to 0.5 . The drying times obtained in this present study was extremely low compared the results obtained in the previous studies given in literature. Therefore, convective drying is long and causes many undesirable changes in the shrimp.

As seen in Fig. 4, the drying rate increased rapidly at the beginning, attained a maximum value at about 2 minute followed by a gradual decrease. In general, it observed that drying rate reduces with time or with the reduction of moisture content. As mentioned earlier, the product's moisture content reduces over time. The drying process took place in the falling rate period. It was observed that, one of the main factors influencing the drying kinetics of the product is the drying microwave power during the falling rate drying period. Lahsasni et al. (2004) reported that the drying during the falling rate period is so governed by water diffusion in the solid. 
Moisture movement to the surface and rate of moisture vaporisation from surface to air reduces with the reduction of moisture content in the product. For that reason, drying rate also reduces in time. As shown in Fig. 1, the high drying rate at high microwave power could be due to more heating energy which speeds up the movement of water molecules and results in higher moisture diffusivity. But, Hu et al. (2006) reported that too high microwave power drying has been associated with physical damages to the products. They found that it is difficult to control the quality of the dried products when higher power densities are used. Similar results have been reported by Varith et al. (2007); Akpinar et al. (2003); Togrul and Pehlivan (2002); Hu et al. (2006) and Alibas (2007).

\subsection{Calculation of diffusion coefficient}

The effective moisture diffusivities at different microwave powers are shown in Fig. 4. It can be seen that the values of $\mathrm{D}_{\text {eff }}$ increased greatly with increasing microwave power. The effective diffusivities of shrimp were $1.54 \times 10^{-10}, 7.72 \times 10^{-10}, 1.23 \times 10^{-9}$ and $1.43 \times 10^{-9} \mathrm{~m}^{2} / \mathrm{s}$ at $200,300,400$ and $500 \mathrm{~W}$, respectively. The values lie within the general range of $10^{-11}-10^{-9} \mathrm{~m}^{2} / \mathrm{s}$ for food materials (Madamba et al., 1996). The increase in microwave power resulted in rapid heating of the product, thus increasing the vapour pressure inside the product that made the diffusion of moisture towards the surface faster. The relationship between microwave power and moisture diffusivity can be represented as:

$$
\mathrm{D}_{\text {eff }}=9 \times 10^{-15} \mathrm{P}^{2}+1 \times 10^{-11} \mathrm{P}-2 \times 10^{-9} \quad \mathrm{R}^{2}=0.997
$$

where $\mathrm{P}$ is microwave power $(\mathrm{W})$.

\subsection{Energy efficiency of microwave drying}

Change of microwave drying efficiency and specific energy consumption are shown in Fig. 5. According to Fig. 5 , microwave drying efficiency and specific energy consumption decreased and increased with increase in microwave power from 4.174 to $3.237\left(\mathrm{MJ} / \mathrm{kg}\left[\mathrm{H}_{2} \mathrm{O}\right]\right)$ and 54.07 to $69.72 \%$, respectively. As a result, the energy consumption in the drying processes carried out at low microwave power levels yielding longer drying period was determined to be in higher rates. This phenomenon agreed with the drying characteristics of many bioproducts under thin layer drying (Alibas, 2007; Araszkiewicz et al., 2004; Mousa and Farid, 2002; Soysal et al., 2004; Yongsawatdigul and Gunasekaran, 1996; Tulasidas et al., 1995). Araszkiewicz et al. (2004) and Mudgett (1982) reported that the dielectric properties of the product being dried are proportionally related to moisture content. Thus, intensity of heat generation or the ability of the product to absorb microwave energy decreases due to the reduction of moisture during the microwave drying process (Soysal et al.. 2004).

The specific energy consumption obtained in the drying process using $400 \mathrm{~W}$ microwave power level was $5.88 \%$ higher than $300 \mathrm{~W}$ microwave power level.

\section{Conclusion}

The thin layer drying behaviour of shrimp in a laboratory microwave dryer was examined at microwave powers from 200 to $500 \mathrm{~W}$. The following conclusions can be drawn from the study.

(1) Drying process took place only in the falling rate period for shrimp.

(2) Approximately $3.093 \mathrm{~kg}\left[\mathrm{H}_{2} \mathrm{O}\right] / \mathrm{kg}[\mathrm{DM}]$ of the moisture content was removed in this period.

(3) The drying time reduced by about 3.13 times on increasing microwave power from 200 to $500 \mathrm{~W}$.

(4) Drying rate decreased with increasing drying time and decreasing moisture content.

(5) The effective diffusivity increases as microwave power increases.

(6) In contrast, increasing drying microwave power increased drying efficiency and decreased specific energy consumption.

\section{References}

Akpinar, E. K; Bicer, Y, and Yildiz, C. (2003). Thin layer drying of red pepper. Journal of Food Engineering, 59: 99-104.

Alibas, I. (2007). Energy consumption and colour characteristics of nettle leaves during microwave, vacuum and convective drying. Biosystems Engineering, 96 (4): 495-502.

Araszkiewicz, M, Koziol, A, Oskwarek, A, and Lupinski, M. (2004). Microwave drying of porous materials. Drying Technology, 22(10): 2331-2341.

Devahastin, S, Tapaneyasin, R, and Tansakul, A. (2006). Hydrodynamic behavior of a jet spouted bed of shrimp. Journal of Food Engineering, 74(3): 345-351. 
Guochen, Z, Arason, S, and Arnason, S. A. (2009). Dehydration property of shrimp (Pandalus borealis) undergoing heat-pump drying process. International Journal Agriculture \& Biology Engineering, 2(4): 92-97.

Hayes, G. D. (1987). Food Engineering Data Handbook. Longman Scientific and Technical, England.

Hu, Q. G, Zhang, M, Mujumdar, A. S, Xiao, G. N, and Sun, J. C. (2006). Drying of edamames by hot air and vacuum microwave combination. Journal of Food Engineering, 77: 977-982.

Jayasinghe, P. S, Jayasinghe, J. M. P. K, and Galappaththi, C. P. (2006). Influence of different processing methods on quality and shelf life of dried shrimp. Sri Lanka Journal Aquatic Science, 11: 85-91.

Khraisheh, M. A. M, McMinn, W. A. M, and Magee, T.R.A. (2004). Quality and structural changes in starchy foods during microwave and convective drying. Food Research International, 37: 497-503.

Lahsasni, S, Kouhila, M, Mahrouz, M, and Jaouhari, J. T. (2004). Drying kinetics of prickly pear fruit (Opuntia ficus indica). Journal of Food Engineering, 61: 173-179.

Lin, T.M, Durance, T. D, and Scaman, C. H. (1999). Physical and sensory properties of vacuum microwave dehydrated shrimp. Journal of Aquatic Food Product Technology, 8: 41-53.

Madamba, P. S, Driscoll, R. H, and Buckle, K. A. (1996). Enthalpy-entropy compensation models for sorption and browning of garlic. Journal of Food Engineering, 28: 109-119.

Mousa, N, and Farid, M. (2002). Microwave vacuum drying of banana slices. Drying Technology, 20(10): 2055-2066.

Mudgett, R. E. (1982). Electric properties of foods in microwave processing. Food Technology, 36(2): 109-115.

Namsanguan Y., Tia W., Devahastin S., and Soponronnarit, S. (2004). Drying kinetics and quality of shrimp undergoing different two-stage drying processes. Drying Technology, 22(4): 759-778.

Namsanguan, Y. (2007). Drying of shrimp using hybrid superheated steam and heat pump dryers, Thiess Ph.D, King Mongkut's University Technology Thonburi, Bangkok.

Namsanguan, Y, Tichangton, S, Tia, W, Soponronnarit, S, and Devahastin, S. (2005). Simulation of a mixed air and superheated steam drying system. Drying Technology, 23: 25-248.

Niamnuy, C, Devahasstin, S, Soponronnarit, S, and Raghavan, G. S. V. (2008a). Kinetics of astaxanthin degradation and color changes of dried shrimp during storage. Journal of Food Engineering, 87: 591-600.

Niamnuy, C, Devahasstin, S, Soponronnarit, S, and Raghavan, G. S. V. (2008b). Modeling coupled transport phenomena and mechanical deformation of shrimp during drying in a jet spouted bed dryer. Chemistry Engineering Science, 63: 5503-5512.

Ozbek, B, and Dadali, G. (2007). Thin-layer drying characteristics and modelling of mint leaves undergoing microwave treatment. Journal of Food Engineering, 83: 541-549.

Ozkan, I. A, Akbudak, B, and Akbudak, N. (2007). Microwave drying characteristics of spinach. Journal of Food Engineering, 78: 577-583.

Prachayawarakorn, S, Soponronnarit, C, Wetchacama, S, and Jaisut, D. (2002). Dessorption isotherms and dryin characteristics of shrimp in superheated steam and hot air. Drying Technology, 20: 669-684.

Reyes, A, Ceron, S, Zuniga, R, and Moyano, P. (2007). A comparative study of microwave-assisted air drying of potato slices. Biosystems Engineering, 98: 310-318.

Sharma, G. P, and Prasad, S. (2004). Effective moisture diffusivity of garlic cloves undergoing microwave-convective drying. Journal of Food Engineering, 65: 609-617.

Soysal, Y. (2004). Microwave drying characteristics of parsley. Biosystems Engineering, 89: 167-173.

Soysal, Y, Oztekin, S, and Eren, O. (2006). Microwave drying of parsley: modelling, kinetics, and energy aspects. Biosystems Engineering, 93 (4): 403-413.

Tapaneyasin, R, Devahastin, S, and Tansakul, A. (2005). Drying methods and quality of shrimp during in a jet-spouted bed dryer. Journal of Food Process Engineering, 28: 35-52.

Thanin, S, and Salakphet, C. (1998). Drying of shrimp using spouted bed dryer and a combined microwavel spouted bed dryer. Project report (B. Eng. Mechanical Engineering), King Mongkut's University of Technology Thonburi, Thailand. 
Tichangtong, S. (2001). Development of Prototype of Shrimp Dryer Using Superheated Steam, Thiess MC.s, Thermal Technology, National Research Council of Thailand, Thailand.

Tulasidas, T. N, Raghavan, G. S. V, and Mujumdar, A. S. (1995). Microwave drying of grapes in a single mode cavity at $2450 \mathrm{MHz}-\mathrm{II}:$ Quality and energy aspects. Drying Technology, 13(8): 1973-1992.

Vadivambal, R, and Jayas, D. S. (2007). Changes in quality of microwave-treated agricultural products-a review. Biosystems Engineering, 98: 1-16.

Varith, J, Dijkanarukkul, P, Achariyaviriya, A, and Achariyaviriya, S. (2007). Combined microwave-hot air drying of peeled longan. Journa of Food Engineering, 81: 459-468.

Visetsuntorn, P, and Banjong, K. (2010). Application of image processing to analyze surface characteristics of shrimp during drying. The $5^{\text {th }}$ Conference on Science and Technology for Youths.

Yongsawatdigul, J, and Gunasekaran, S. (1996). Microwave-vacuum drying of cranberries:-Part I: energy use and efficiency. Journal of Food Processing and Preservation, 20: 121-143.

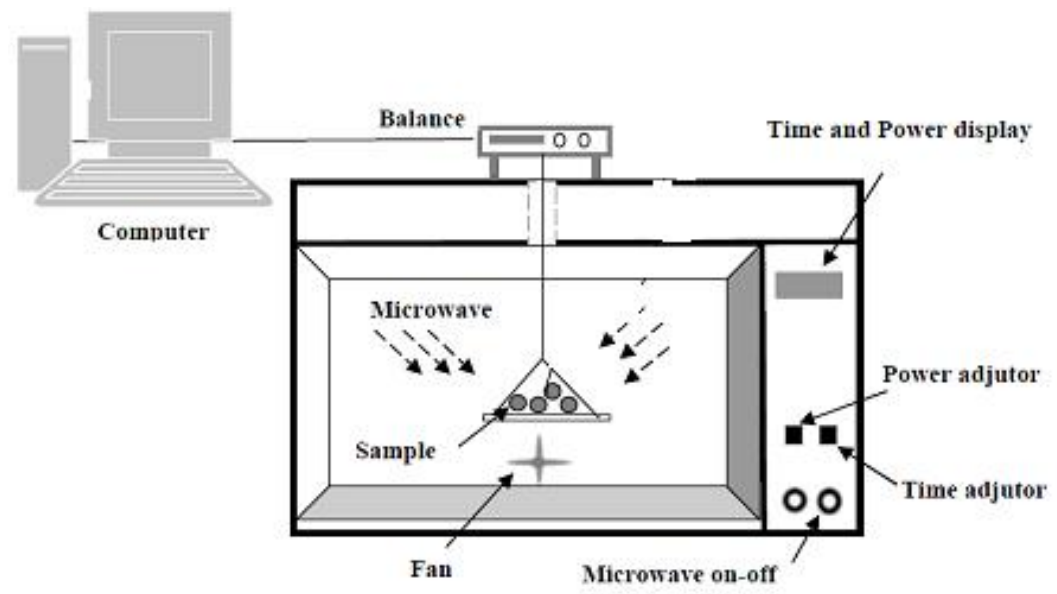

Figure 1. Diagram of microwave drying system

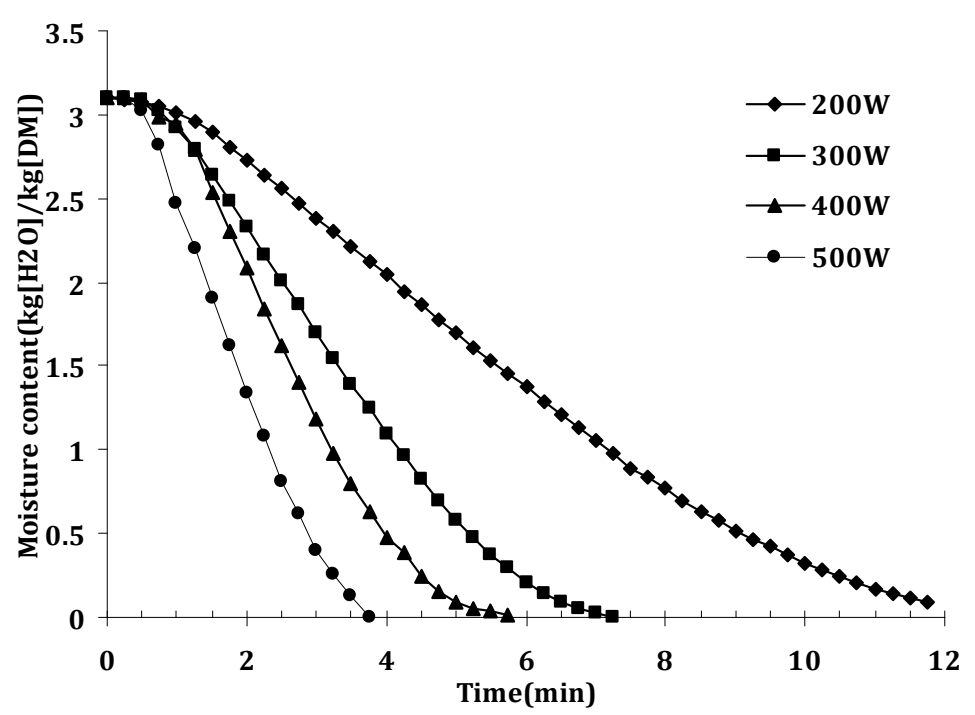

Figure 2. The relations of moisture content and drying time at different microwave powers 


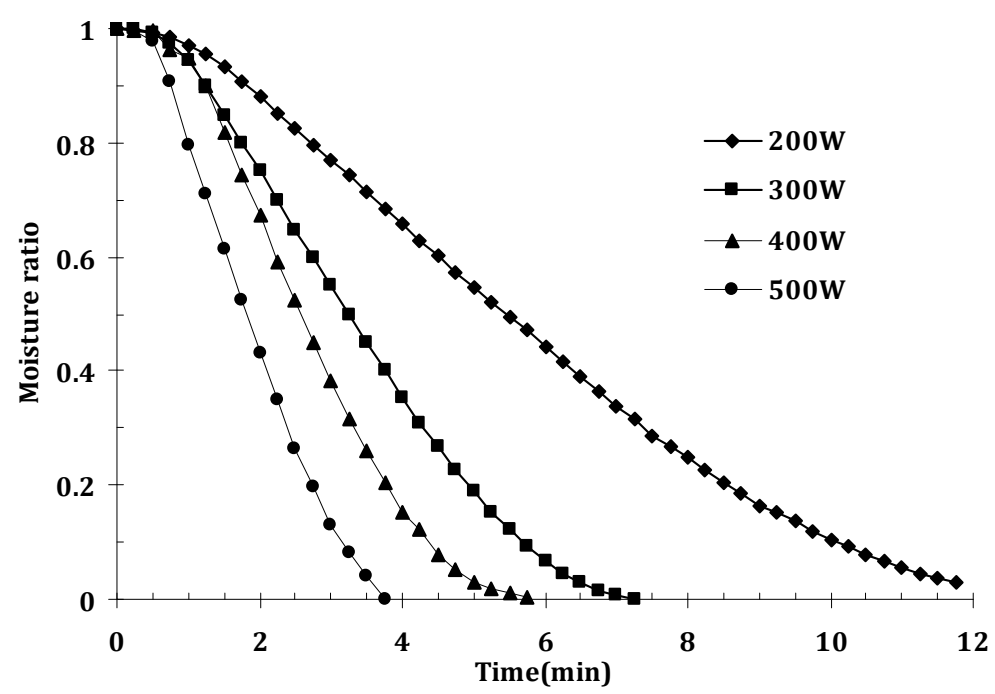

Figure 3. Drying curves of shrimp at different microwave powers
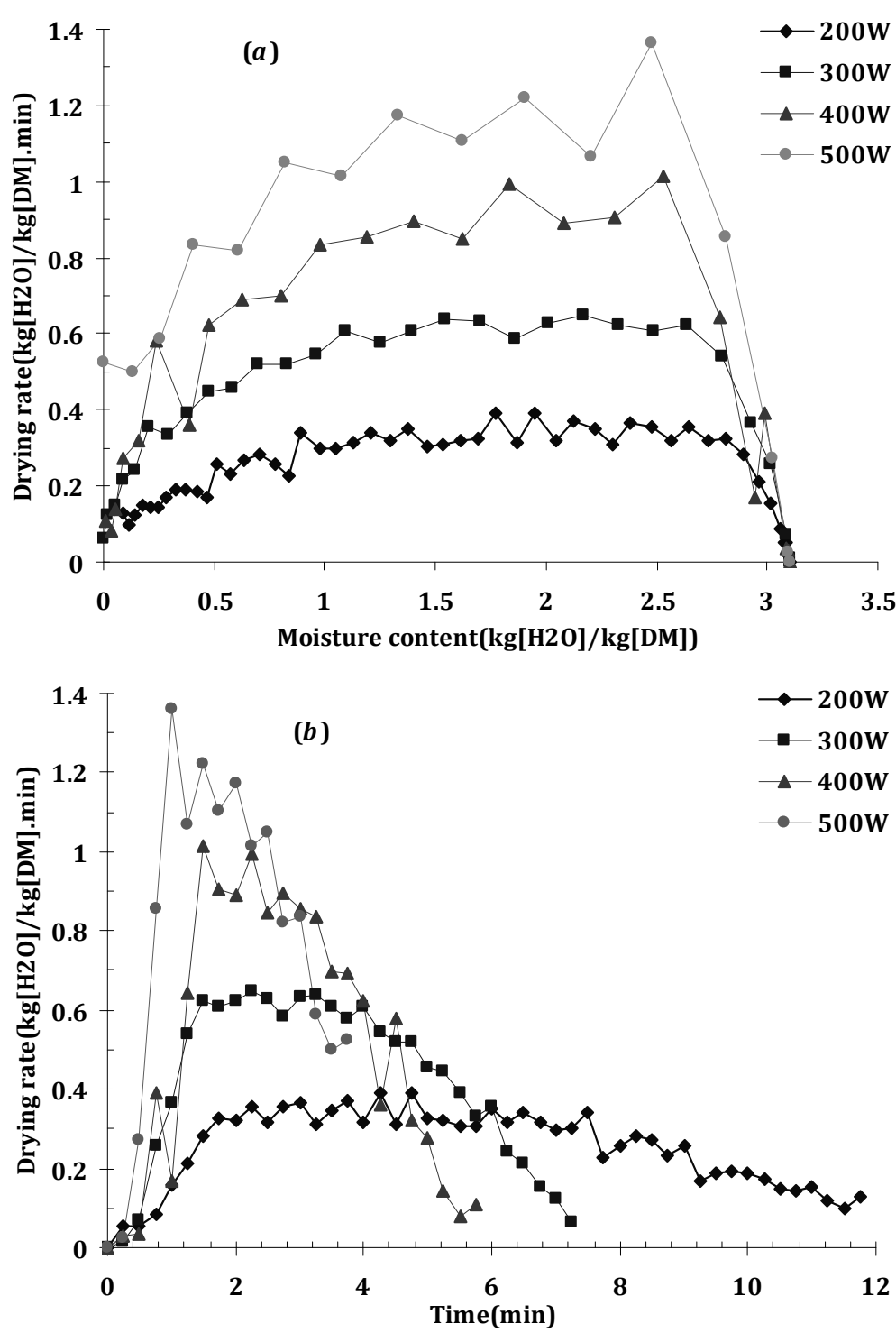

Figure 4. The relations of drying rate and (a) moisture content and (b) drying time at different microwave powers 


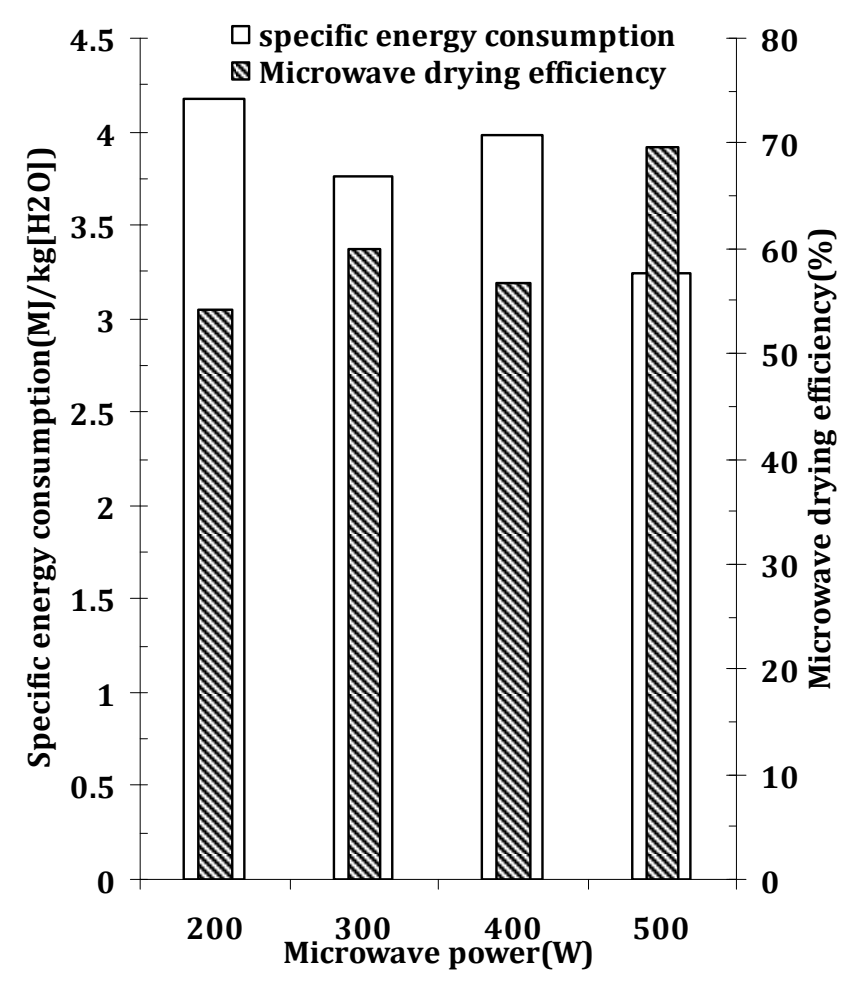

Figure 5. Microwave drying efficiency and specific energy consumption at different microwave powers

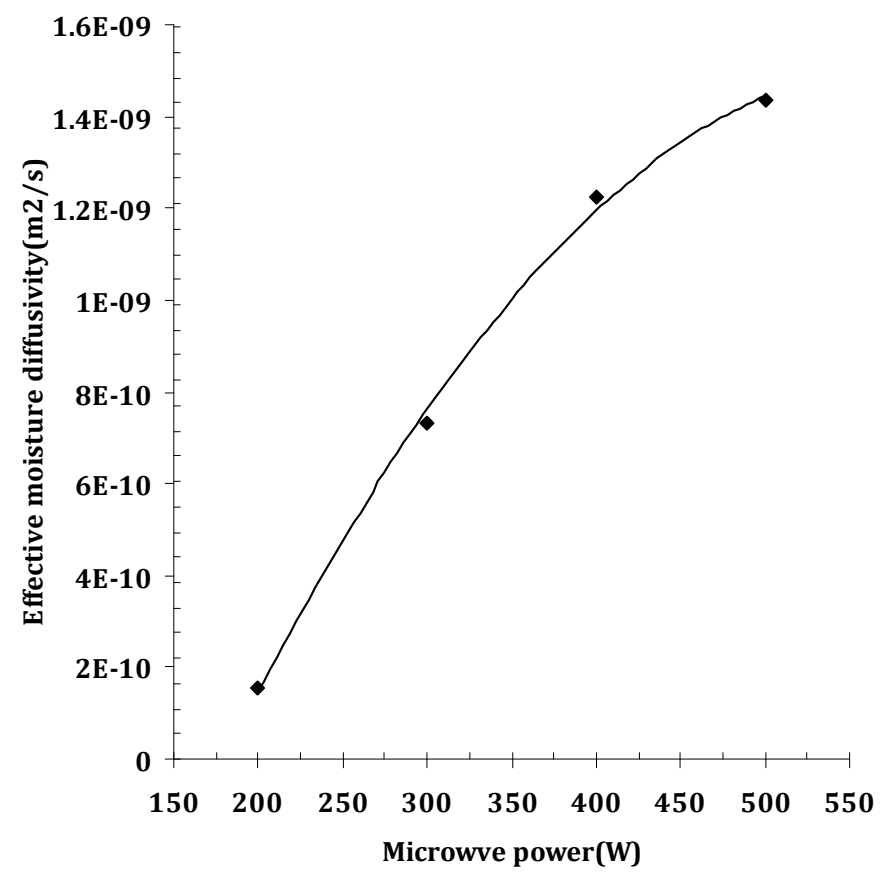

Figure 6. Effective diffusivities of shrimp dried at different microwave output powers 